УДК $523.2+532.5$

\title{
ІНВАРІАНТНІ ВЛАСТИВОСТІ ВИХРОВИХ КІЛЕЦЬ ПЛАНЕТАРНОГО ВИХОРУ ТА ЇХ ВПЛИВ НА ЕВОЛЮЩЮ ВИХОРУ
}

\author{
${ }^{*}$ В. I. Перехрест, ${ }^{* *}$ Л. В. Ключинська
}

* Дніпропетровсъкий начіональний універсистет ім. Олеся Гончара, 49050, Дніпропетровськ. E-mail: prokhrest@i.ua

** Севастопольсъкий інститут банківсъкої справи

Установлено кілька важливих властивостей руху частинок течії у планетарному вихорі, що стосуються розподілів їх кутових моментів та кутових швидкостей. Виявлено, що вказані властивості при дії на вихор гравітаційної сили зірки спричиняють сплющення кілець та їх значну міграцію від первинних положень. При цьому кільця перетинаються, що сприяє стиканню й злипанню частинок та утворенню твердих планет.

Ключові слова. планетарний вихор, еволюція вихрових кілець.

\section{1. Вступ}

Теорія планетарного вихору, розвинута у наших попередніх роботах $[1,2]$ продемонструвала високий рівень адекватності з реальністю стосовно глобальних характеристик планетарних систем, таких як: кількість планет у системі, їх орбітальні відстані та швидкості обертання [3]; кутові моменти та власне обертання малих тіл і астероїдів [4] тощо. Із цих загальних властивостей первинного вихору випливає, що вихрове збурення газопилової туманності фрагментуе область туманності на кільцеві вихрові зони, у яких повинні сформуватися зародки планет, а потім і самі планети. Така модель обгрунтована вже тим, що обчислені глобальні параметри остаточно сформованої планетарної системи Сонця на основі оцінок об'ємів та кутових моментів вихрових зон при подальшому застосуванні законів збереження дали реальні величини планетних відстаней та кутових моментів у Сонячній системі [3-6]. Закономірно виникає потреба дослідити і пояснити сам процес збирання пилу, частинок і газів у тверду планету з газовою атмосферою.

До сьогодні в астрономічній науці немає єдиного погляду й обгрунтованої теорії утворення з планетарної туманності зірок і планет. Домінуе погляд про статистично-випадкове виникнення в туманності неоднорідностей густини чи тиску, які спричиняють конденсацію й акрецію, а потім гравітаційну нестабільність, - більшість відповідних моделей і оцінок грунтуються на відомому

(C) В. I. Перехрест, Л. В. Ключинська, 2013 
критерії Дж. Джинса [12]. Якщо слідувати цій логіці, то випадковий характер утворення планетозималей викликав би і випадковий розподіл планетних відстаней. Між тим, приклади Сонячної та численних екзопланетарних систем [14] говорять про єдину закономірність розподілу планетних відстаней: iз збільшенням номерів планет відстані між сусідніми планетами збільшуються. Теоретичний закон із такою властивістю було отримано на основі вихрової теорії в [5].

Недостатність або й некоректність багатьох теорій нестабільності газопилового диска була відзначена вже у середині XX століття $[7,8]$ попри те, що у моделі виникнення нестабільностей закладалися все нові фізичні чинники: збурення термодинамічних полів та полів тиску або густини, наявність первинних завихрень і турбулентності тощо. В останні десятиліття були розвинуті потужні чисельно-аналітичні комп'ютерні технології розрахунку гідродинамічних процесів у протопланетних дисках з урахуванням термодинамічних ефектів та різних неоднорідностей розподілів фізичних характеристик туманності. Це такі програми як AMR-code (R. J. Klien at all [9]), SPHcode (A. Burkert [9]), RAPID-code (N. Murray [11]), сферичні сітки (A. Boss, P. Bodenheimer $[9,10])$ та ін. При цьому в початкові чи граничні умови вносяться якісь збурення густини, тиску, температури та ін., які при чисельній реалізації інколи породжують певні нестабільні вихрові форми. На жаль, часто результати розрахунків за різними схемами $є$ непорівнянними, а у цілому приводять до висновків на зразок такого: "Хоча були розглянуті різні правдоподібні ідеї, загальної відповідності теорії та спостережень до цього часу не було виявлено" [9].

Нижче досліджуються деякі гетерогонічні інваріантні характеристики вихрових кілець первинного вихору, з яких випливають закономірності їх еволюції, що зумовлюють формування з кільця планетного тіла з реальними характеристиками руху.

\section{2. Геометрія та кінематика вихрових кілець}

Розглянемо точний розв'язок гідродинамічних рівнянь Ейлера [1], що описує просторовий осесиметричний вихор із кількома внутрішніми та зовнішніми вихровими кільцями [3]. Функція течії $\Psi(y, \theta)$ цього вихору в неперервному випадку має вигляд:

$$
\Psi=C_{2} \Phi(y) \sin ^{2} \theta, \quad \Phi(y)=\alpha y^{2}+\left(\cos y-\frac{\sin y}{y}\right),
$$

де $r, \theta, \varphi$ - сферичні координати, $y=C_{0} r$ - безрозмірний радіус, $C_{0}, C_{2}-$ параметри.

Поле швидкостей течії, породженої функцією (2.1), згідно із залежностями

$$
V_{r}=-2 B \frac{\Phi(y)}{y^{2}} \cos \theta, \quad V_{\theta}=B \frac{\Phi^{\prime}(y)}{y} \sin \theta, \quad V_{\varphi}=B \frac{\Phi(y)}{y} \sin \theta
$$


остаточно має вигляд:

$$
\begin{aligned}
& V_{r}=-2 B\left(\alpha+\frac{1}{y^{2}}\left(\cos y-\frac{\sin y}{y}\right)\right) \cos \theta \\
& V_{\theta}=B\left(2 \alpha-\frac{\sin y}{y^{2}}-\frac{1}{y^{2}}\left(\cos y-\frac{\sin y}{y}\right)\right) \sin \theta ; \\
& V_{\varphi}=B y\left(\alpha+\frac{1}{y^{2}}\left(\cos y-\frac{\sin y}{y}\right)\right) \sin \theta,
\end{aligned}
$$

де $B=C_{2} C_{0}^{2}$ - параметр із розмірністю швидкості.

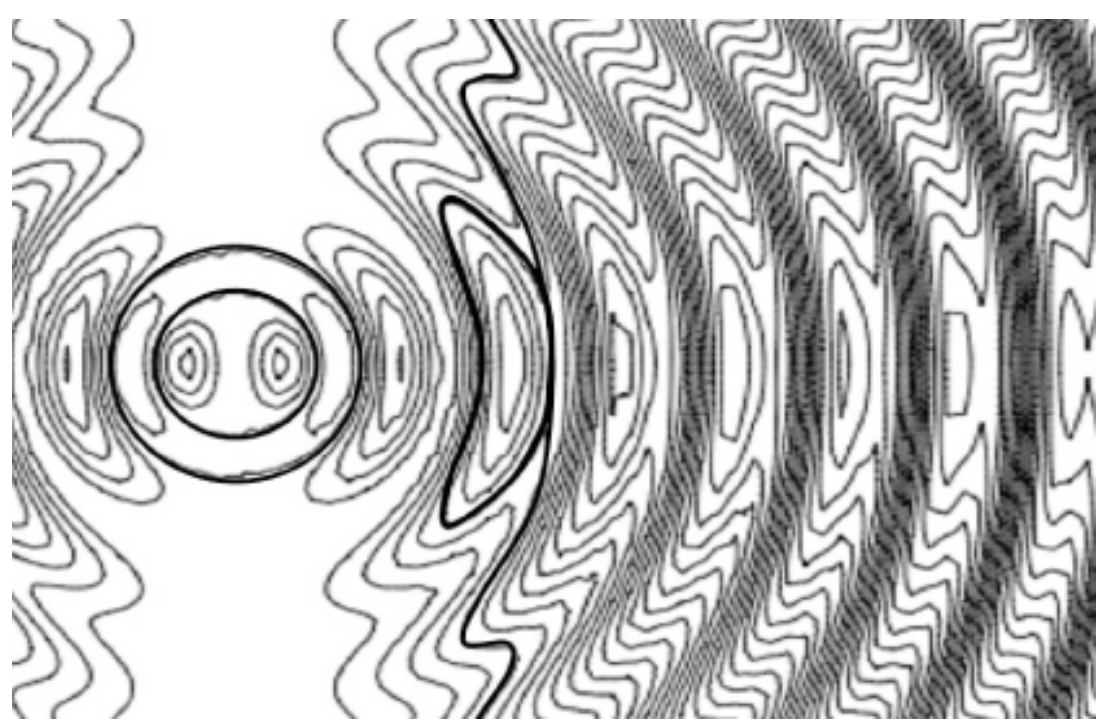

Рис. 1: Лінії течії та вихрові кільця планетарного вихору

Геометрична картина поля ліній течії , породженої функцією (2.1) за формулою

$$
\Psi \equiv \Phi(y) \sin ^{2} \theta=C
$$

являе собою низку тороїдних вихрових кілець, частина з яких $(n)$ заповнюють кілька замкнутих непроникних сфер, а зовнішні $(m)$ кілець вільно висять у просторі й обтікаються незамкнутими лініями течії (рис. 1). У цілому, дана течія складається з гвинтового руху закрученого простору, на який накладається поле вихрового диполя у початку координат, - взаємодія цих течій і породжує планетарний вихор. Структури $(n, m)$ вихору визначаються параметром $\alpha$ у виразі $(2.1)$, який виражає співвідношення між інтенсивностями складових рухів, а саме:

$$
\alpha=-V_{\infty} /\left(2 C_{2} C_{0}^{2}\right),
$$

де $V_{\infty}$ - поступальна швидкість простору, $C_{0}$ - параметр закручування простору, $C_{2}$ - інтенсивність або момент центрального диполя. 
Будемо вважати, що до виникнення центрального диполя, який породив вихор, планетарна туманність мала квазітвердий гвинтовий рух зі швидкістю $V_{\infty}$ та обертанням $\omega_{\infty}=-0,5 \cdot C_{0} V_{\infty}$, причому вона перебувала у стані термодинамічної рівноваги. Далі ми оцінимо параметри вихрового збурення цього стану, яке при взаємодії з гравітаційним полем молодої зірки спричиняє значні міграції та кардинальну перебудову первинного вихору.

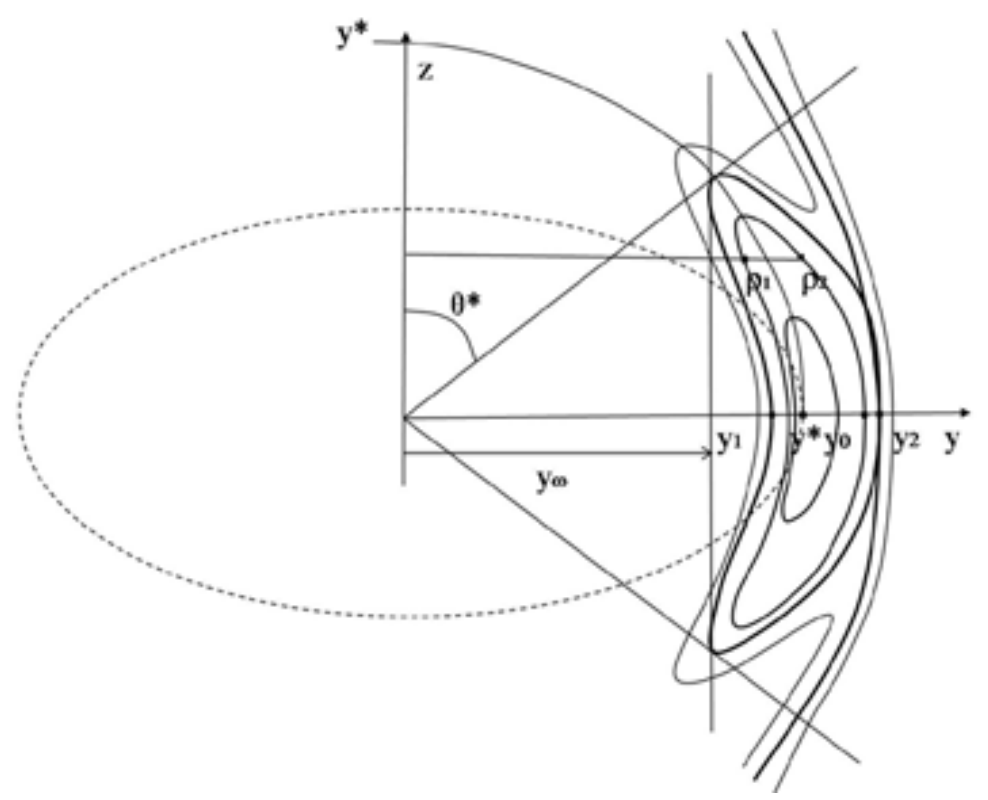

Рис. 2: Геометрія зовнішніх вихрових кілець

Розглянемо поля швидкостей та кутових моментів у межах області вихрового кільця, яке утворене петлею сепаратриси і має геометричні характеристики (рис. 2): $y^{*}$ - радіус центрального кола тороїда; $\pi-2 \theta^{*}$ - кутовий розмір кільця; $y_{2}$ - радіус точки самоперетину сепаратриси; $y_{1}$ - найменший радіус зони кільця у горизонтальній площині $\theta=\pi / 2$. За топологією векторного поля швидкостей $(2.3)$ точки $\left(y^{*}, y_{2}\right)$ є особливими точками, причому $y^{*}$ є «центрами», а $y_{2}-$ «сідлами», їх радіуси $y^{*}, y_{2} \in$ послідовними розв'язками трансцендентного рівняння

$$
\Phi^{\prime}(y)=0 .
$$

У таблиці 1 дано ці геометричні характеристики вихрових кілець планетарного вихору структури $(2,11)$, яким у попередніх працях [3-5] моделювалась Сонячна система. Для перших двох кілець вказано радіуси двох замкнутих сфер, у яких містяться ці кільця.

Очевидно, що у вузлі сепаратриси з координатами $\left(y_{2}\right)$ з (2.4) маємо

$$
\Phi(y) \sin ^{2} \theta=\Phi\left(y_{2}\right)
$$


- це і є ïi рівняння, яке можна записати ще у вигляді:

$$
\theta=\arcsin \sqrt{\frac{\Phi\left(y_{2}\right)}{\Phi(y)}} .
$$

Враховуючи, що граничний кут $\theta^{*} \in$ мінімальним значенням на сепаратриci $(2.8)$, з умови екстремуму $\theta^{\prime}(y)=0$ маємо $\Phi^{\prime}(y)=0$, що збігається з рівнянням (2.6), якому задовольняе значення $y=y^{*}$. Тому

$$
\theta^{*}=\arcsin \sqrt{\frac{\Phi\left(y_{2}\right)}{\Phi\left(y^{*}\right)}}
$$

- граничний кут вихрового кільця. Граничну точку радіального розміру кільця $y_{1}$ знайдемо 3 рівняння сепаратриси $(2.8)$ при $\theta=\pi / 2$, що приводить до рівняння

$$
\Phi(y)=\Phi\left(y_{2}\right),
$$

причому треба знаходити перше рівняння (2.10), що задовольняє умові $y_{1}<$ $<y^{*}$. Можна довести, що цей корінь є єдиним. Таким чином визначаються усі геометричні характеристики кожного з 11 зовнішніх вихрових кілець (табл. 1).

Таблиця 1: Геометричні характеристики кілець планетарного вихору $(2,11)$

\begin{tabular}{|c|c|c|c|c|c|}
\hline № вихору & $y_{1}$ & $y^{*}$ & $y_{2}$ & $\theta^{*}$ рад. & $\Delta$ \\
\hline 1-Сонце & 0,00000 & 2,79026 & 4,63822 & 0 & 1 \\
\hline 2-Сонце & 4,63822 & 6,03419 & 7,35970 & 0 & 1 \\
\hline 3(1) & 7,35970 & 9,44279 & 12,3221 & 0,0537 & 0,9999 \\
\hline 4(2) & 14,0547 & 15,8543 & 18,5497 & 0,7736 & 0,7615 \\
\hline $\mathbf{5 ( 3 )}$ & 20,6513 & 22,2420 & 24,7616 & 1,0257 & 0,4653 \\
\hline $\boldsymbol{6}(\mathbf{4})$ & 27,2095 & 28,6239 & 30,9656 & 1,1767 & 0,2731 \\
\hline $\mathbf{7 ( 5 )}$ & 33,7492 & 35,0055 & 37,1635 & 1,2780 & 0,1596 \\
\hline $\boldsymbol{8 ( 6 )}$ & 40,2812 & 41,3897 & 43,3550 & 1,3511 & 0,0927 \\
\hline $\mathbf{9 ( \boldsymbol { 7 } )}$ & 46,8139 & 47,7794 & 49,5389 & 1,4068 & 0,0525 \\
\hline $\mathbf{1 0}(\mathbf{8})$ & 53,3562 & 54,1779 & 55,7124 & 1,4512 & 0,0282 \\
\hline $\mathbf{1 1 ( 9 )}$ & 59,9207 & 60,5908 & 61,8704 & 1,4882 & 0,0135 \\
\hline $\mathbf{1 2 ( 1 0 )}$ & 66,5325 & 67,0306 & 68,0009 & 1,5209 & 0,0049 \\
\hline $\mathbf{1 3 ( 1 1 )}$ & 73,2830 & 73,5428 & 74,0584 & 1,5529 & 0,0006 \\
\hline
\end{tabular}

Аналогічно, на інших замкнутих лініях течії всередині кільця, які проходять через точки $y=y_{0}$, їх рівняння та граничні кути виражаються формулами $(2.8),(2.9)$, де замінено $y_{2} \rightarrow y_{0}$, а $y_{1} \rightarrow y_{01}$. Тому маємо таке загальне геометричне

Твердження 2.1. Усі вершини торових кілець усередині їх обмежного кільця лежать на колі радіуса $y=y^{*}$, тобто на радіусі центрального кола кільця. 
У вихорах визначальну роль відіграє обертання. 3 формул (2.3) видно, що усі компоненти швидкості мають систематичну складову - константу або лінійну функцію - та квазіперіодичну, яка зникає на нескінченності. Точніше:

$$
\begin{aligned}
& V_{r} \cong\left\lfloor-2 B \alpha+O\left(y^{-2}\right)\right\rfloor \cos \theta, \\
& V_{\theta} \cong\left[2 B \alpha+O\left(y^{-1}\right)\right] \sin \theta, \\
& V_{\varphi} \cong\left[B \alpha y+O\left(y^{-1}\right)\right] \sin \theta,
\end{aligned}
$$

звідки видно, що обертальна швидкість завдяки квазітвердому обертанню лінійно зростає за циліндричним радіусом $\rho$. Відповідна кутова швидкість обертання $\omega=V_{\varphi} / r \sin \theta$ у вихорі дорівнює

$$
\omega=B C_{0} \frac{\Phi(y)}{y^{2}}=\tilde{B}[\alpha+u(y)]
$$

де

$$
\tilde{B}=B C_{0}, \quad u=\frac{1}{y^{2}}\left(\cos y-\frac{\sin y}{y}\right)
$$

- коливна квазіперіодична функція з властивостями $u(0)=-1 / 3, \lim _{y \rightarrow \infty} u(y)=$ $=0 \mathrm{i}$, крім того, $\omega_{\infty}=\lim _{y \rightarrow \infty} \omega(y)=\tilde{B} \alpha$, що узгоджується з $(2.5)$.

Для осьової ж швидкості маємо:

$$
V_{Z}=V_{r} \cos \theta-V_{\theta} \sin \theta, \quad \lim _{y \rightarrow \infty} V_{Z}=-2 B \alpha=V_{\infty}
$$

що теж узгоджується з (2.5).

Отже, з (2.12) випливає

Твердження 2.2. Кутова швидкість обертання частинок у вихорі (2.12) залежить тільки від радіуса $y$ i, значить, вона $є$ сталою на будь-яких сферах $y=y_{0}$, тобто усілякі сфери у вихорі обертаються як тверді тіла з кутовими швидкостями (2.12).

Це твердження стосується тільки поля обертальних швидкостей. Звідси та 3 твердження 2.1 випливає

Твердження 2.3. У межах вихрового кільця скелетною лінією, яка проходить через усі вершини внутрішніх кілець, є коло радіуса $y^{*}$, і кутова швидкість у цих вершинах є сталою величиною $\omega^{*}$, тобто швидкістю обертання центрального кола вихрового кільця.

Подамо обертальну швидкість (3) у вихорі виразом

$$
V_{\varphi}=\omega(y) \rho,
$$

де $\rho=r \sin \theta$ - циліндричний радіус. 
Обчислимо кутовий момент частинок вихору відносно осі Oz:

$$
I_{Z}=(r \times V)_{Z}=V_{\varphi} \rho=\omega(y) \rho^{2}=\beta \Phi(y) \sin ^{2} \theta,
$$

де $\omega$ - кутова швидкість (2.12), $\beta=C_{0} C_{2}$ - параметр із розмірністю кутового моменту.

Очевидно, що на лініях течії (2.12), які при $\theta=\pi / 2$ виходять із точки $y_{0}$, виконуеться рівність

$$
\beta \Phi(y) \sin ^{2} \theta=I_{0}, \quad I_{0}=\beta \Phi\left(y_{0}\right),
$$

де $y^{*} \leq y_{0} \leq y_{2}$, тобто має місце

Твердження 2.4. Лінії течії (2.4) є одночасно й ізолініями значень осьового кутового момента, який за $(2.16)$ визначається в точці $y=y_{0}$ на горизонтальній осі.

3 іншого боку, порахуємо кутові моменти точок кола $y=y^{*}$ у межах $\theta^{*} \leq \theta \leq \pi / 2$, тобто у вершинах кільцевих ліній течії всередині вихрового кільця з граничною координатою $\theta=\theta_{0}$. Вони дорівнюють:

$$
I_{Z}^{*}=\beta \Phi\left(y_{*}\right) \sin ^{2} \theta_{0}, \quad \theta^{*} \leq \theta_{0} \leq \pi / 2,
$$

звідки випливає, що на колі $y=y^{*}$ у межах кільця

$$
\begin{aligned}
& \left(I_{Z}\right)_{\max }=I_{*}=\beta \Phi\left(y_{*}\right), \\
& \left(I_{Z}\right)_{\min }=I_{*} \sin ^{2} \theta^{*},
\end{aligned}
$$

звідки з урахуванням твердження 2.4 випливає $I_{*} \sin ^{2} \theta^{*} \leq I_{0} \leq I_{*}$, тобто

Твердження 2.5. У межах вихрового кільця кутовий момент точок центрального кола є максимальним порівняно з кутовими моментами точок, що лежать на усіх тороїдах кільця і мають зображення (2.16). Відповідно, мінімальним є кутовий момент у точках обмежної сепаратриси.

Замкнуту лінію твірної тороїда будемо мітити точкою $y=y_{0},\left(y^{*} \leq y_{0} \leq\right.$ $\left.\leq y_{2}\right)$ на горизонтальній осі. Вона перетинає коло $y=y^{*}$ у точці з кутом $\theta=\theta_{0}$, i за $(2.16)$ і (2.17) маємо:

$$
\Phi\left(y^{*}\right) \sin ^{2} \theta_{0}=\Phi\left(y_{0}\right) .
$$

Але на кожній замкнутій лінії течії у межах $y_{1}<y<y_{2}$ таких точок $є$ дві: $y_{01} y_{0}$ (рис. 2). Значить, $\Phi\left(y_{01}\right)=\Phi\left(y_{0}\right)$. Це узгоджується з теоремою Ролля, що існує значення $y=y^{*},\left(y_{01}<y^{*}<y_{02}\right)$, де $\Phi^{\prime}\left(y^{*}\right)=0$, що справді має місце 3 (2.6).

Візьмемо дві точки 3 циліндричними радіусами $\rho_{1}, \rho_{2}\left(\rho_{1}<\rho_{2}\right)$ на напрямній тора, у яких горизонтальні лінії перетинають тор; їх кутові швидкості $є$ $\omega_{1}, \omega_{2}$ відповідно (рис. 2). 3 умови сталості кутового момента (2.16), твердження 2.4, маємо:

$$
\omega_{1} \rho_{1}^{2}=\omega_{2} \rho_{2}^{2}=I_{0} \Rightarrow \frac{\omega_{1}}{\omega_{2}}=\left(\frac{\rho_{1}}{\rho_{2}}\right)^{2} .
$$


Твердження 2.6. Кутові швидкості точок перетину горизонтальних ліній 3 напрямними лініями будь-якого тора є обернено пропорційними квадратам циліндричних радіусів цих точок на торі.

Тому при $\rho_{1}<\rho_{2} \omega_{1}>\omega_{2}$, тобто кутові швидкості на внутрішній півтраєкторії $y_{1}<y<y^{*}$, є більшими, ніж на зовнішній, $y^{*}<y<y_{2}$, а у вершинах кілець $\left(y^{*}, \theta_{0}\right)$, згідно з твердженням $2.3, \rho_{1}=\rho_{2}=\rho^{*}$, а $\omega_{1}=\omega_{2}=\omega^{*}$.

Для лінійних колових швидкостей з умови (2.16) або (2.20) відповідно випливає:

$$
V_{1} \rho_{1}=V_{2} \rho_{2}=I_{0}, \Rightarrow \frac{V_{2}}{V_{1}}=\frac{\rho_{1}}{\rho_{2}},
$$

тобто і лінійні швидкості обертання на внутрішній півтраєкторії також є більшими, ніж на зовнішній в обернено пропорційній залежності.

Таблиця 2: Кінематичні характеристики кілець планетарного вихору $(2,11)$

\begin{tabular}{|c|c|c|c|c|}
\hline № вихору & $y_{\omega}$ & $\omega_{\max } \cdot 10^{-3}$ & $\omega^{*} \cdot 10^{-3}$ & $\omega_{\min } \cdot 10^{-3}$ \\
\hline 1-Сони, & 0 & -340 & -143 & 0 \\
\hline 2-Сонце & 5,763 & 22 & 21 & 0 \\
\hline 3(1) & 9,095 & -18 & -18 & $-0,030$ \\
\hline 4(2) & 15,515 & -11 & -10 & $-6,552$ \\
\hline $\mathbf{5 ( 3 )}$ & 21,854 & $-8,637$ & $-8,486$ & $-5,006$ \\
\hline $\boldsymbol{6}(\mathbf{4})$ & 28,168 & $-7,808$ & $-7,682$ & $-5,596$ \\
\hline $\mathbf{7 ( 5 )}$ & 34,475 & $-7,391$ & $-7,275$ & $-5,917$ \\
\hline $\boldsymbol{8 ( 6 )}$ & 40,767 & $-7,151$ & $-7,041$ & $-6,112$ \\
\hline $\boldsymbol{9}(\mathbf{7})$ & 47,060 & $-7,001$ & $-6,892$ & $-6,242$ \\
\hline $\mathbf{1 0}(\mathbf{8})$ & 53,351 & $-6,901$ & $-6,791$ & $-6,331$ \\
\hline $\mathbf{1 1 ( 9 )}$ & 59,640 & $-6,831$ & $-6,716$ & $-6,397$ \\
\hline $\mathbf{1 2 ( 1 0 )}$ & 65,928 & $-6,782$ & $-6,656$ & $-6,452$ \\
\hline $\mathbf{1 3 ( 1 1 )}$ & 87,931 & $-6,721$ & $-6,642$ & $-6,506$ \\
\hline
\end{tabular}

Отже, при русі вздовж траєкторії від внутрішньої точки $y_{01}$ до зовнішньої $y_{0}$ кутова швидкість обертання $\omega(y)$ на відрізку $\left[y_{1}, y_{2}\right]$ є спадною, а величина $\omega^{*} \in$ деяким її середнім значенням. Порівнюючи функції $\omega(y)$ і $\Phi(y)$, врахуємо, що радіуси $\left(y^{*}, y_{2}\right)$ задовольняють умові $(2.6)$, тобто є екстремальними для функції $\Phi(y)$, причому

$$
\begin{aligned}
& \left|\Phi\left(y^{*}\right)\right|=\max |\Phi(y)|, \\
& \left|\Phi\left(y_{2}\right)\right|=\min |\Phi(y)| y \in\left[y_{1}, y_{2}\right] .
\end{aligned}
$$

Але умова екстремуму для кутової швидкості (2.12)

$$
\omega^{\prime}(y)=\frac{B C_{0}}{y^{2}}\left(\Phi^{\prime}(y)-\frac{2}{y} \Phi(y)\right)=0
$$


справді відрізняється від умови (2.6) екстремуму функції $\Phi(y)$. Було пораховано корені $y_{\omega}$ рівняння $(2.23)$, яке зводиться до такої форми:

$$
\sin y+\frac{3}{y}\left(\cos y-\frac{\sin y}{y}\right)=0
$$

їх значення $y_{\omega}$ наведено також у таблиці 2. Ці корені справді лежать $y_{\omega}$ межах $y_{1}<y_{\omega}<y^{*}$. Із $(2.20)$ ще випливає, що $\omega=\omega_{\max }$ там, де на тороїдному кільці $\rho=\rho_{\min }$, тобто у двох точках, де вертикальна лінія дотикається до кільця і для яких $y=y_{\omega}$ (рис. 2).

Справді, рівняння тороїдного кільця (2.16) можна перетворити до вигляду

$$
\rho^{2}=\frac{\Phi\left(y_{0}\right) y^{2}}{\Phi(y)}=\frac{\Phi\left(y_{0}\right)}{\alpha+u(y)}
$$

і необхідна умова мінімуму $\left(\rho^{2}\right)^{\prime}=0$ також приводить до рівняння (2.24).

$\mathrm{У}$ таблиці наведено також значення кутових швидкостей $\omega^{*}\left(y^{*}\right)$ центрів кілець та $\omega_{\max }=\omega\left(y_{\omega}\right)$, обчислених із точністю до множника $B=C_{2} C_{0}^{3}$. Очевидно, що у межах кільця $\omega_{\min }=\omega\left(y_{2}\right)$, тобто $є$ швидкістю обертання у вузлах сепаратриси (табл. 2).

\section{3. Еволюція вихрових кілець}

Прослідкуємо, як зміняться параметри руху вагомих частинок вихору (2.3) під дією гравітаційної сили зірки масою $M$, яку «увімкнемо» миттєво, хоча насправді формування зірки відбувається за деякий час, який, втім, є набагато меншим за період утворення її планетарної системи [11]. Первинний розподіл кутових моментів у планетарному вихорі суттєво відрізняється від їх розподілу при кеплеровому обертанні в полі тяжіння зірки [5]. За умови збереження кутового моменту, яка має місце у полі центральної сили тяжіння, його величина $I$ зв'язана з остаточним радіусом рівноважної орбіти $R$ відомим співвідношенням закону Кеплера

$$
I=\sqrt{f M R} .
$$

Кутові моменти рухомих часток замкнутих траєкторій, що проходять через точки $y=y_{0}$ та $y=y^{*}$ горизонтальної осі, зберігають свої значення і за (2.16) дорівнюють, відповідно,

$$
I_{0}=\beta \Phi\left(y_{0}\right), \quad I_{*}=\beta \Phi\left(y^{*}\right),
$$

причому в силу властивості $(2.19) I_{0}<I^{*}$. Якщо за допомогою $(2.25)$ скласти відношення кутових моментів $I^{*}$ та $I_{\min }$ за $(3.2)$, то для їх остаточних радіусів маємо співвідношення

$$
\sqrt{\frac{R_{*}}{R_{\min }}}=\frac{1}{\sin ^{2} \theta_{*}}, \quad R_{\min }=R_{*} \sin ^{4} \theta_{*} .
$$


Для проміжних кілець радіуси рівноважних орбіт за [5] відповідно дорівнюють:

$$
R_{0}=K_{R} \Phi^{2}\left(y_{0}\right)=K_{R} \Phi^{2}\left(y_{*}\right) \sin ^{4} \theta_{0}, \quad R_{*}=K_{R} \Phi^{2}\left(y_{*}\right),
$$

де $K_{R}=\beta^{2} / f M .3$ тієї ж причини за (2.19) маємо:

$$
R_{\min }<R_{0}<R_{*}
$$

Але запас кутового момента $I_{0}$ для усіх точок замкнутої лінії течії-кільця $€$ однаковим, і тому всі вони перейдуть у точку з відстанню $R_{0}\left(y_{0}\right)$, якщо знехтувати вертикальним розміром та рухом у кільцях. Таким чином, усі вихрові кільця будуть сплющуватися до точок і ставати на різні відстані $R\left(y_{0}\right)$ за (3.4). Було пораховано максимальні розкиди

$$
\Delta=\frac{R_{*}-R_{\min }}{R_{*}}=1-\sin ^{4} \theta_{*}
$$

остаточного розміщення матеріалу кілець у полі тяжіння зірки (табл. 1).

У силу (3.4) центральна точка кільця $O^{*}$ займе найдальше положення 3 радіусом $R^{*}$. Очевидно, що при такій перебудові течії центральна точка $O^{*}$ при русі назовні перетне усі зовнішні півкільця замкнутих ліній вихрового кільця. Аналогічно, менші внутрішні кільця пройдуть через більші зовнішні, і при цьому їх частинки будуть стикатися та злипатися. При русі ж до зірки, навпаки, кільця вихорів будуть перетинати центральні кола і перетинатися між собою, але властивість (3.5) збережеться. Це значною мірою сприятиме зіткненню частинок вихрового кільця між собою та з центром, їх накопиченню і акреції та, зрештою, росту центрального тіла. До того ж дуже скоро центральне тіло буде діяти на частки течії своєю гравітацією, яка захоплюватиме пил і частки з деякого околу.

Із таблиці 1 ще видно, що матеріал перших двох вихрових кілець розтягнеться на значні відстані від планети-центра у бік зірки, якщо при близькій взаємодії ці частинки не будуть захоплені тяжінням планети. Якщо при цьому взяти до уваги існування в околі зірки потужного доцентрового гравітаційного та градієнтного полів [2], то стане ясно, чому в більшості відкритих екзопланетарних систем [14] перші планети є найменшими за масою та позбавленими атмосфери: зірка їх максимально «обдирає», затягуючи усі зважені маси до центра, до себе.

\section{Бібліографічні посилання}

1. Перехрест В. I. Новий розв'язок гідродинамічних рівнянь Ейлера для сферичних вихрових течій/ В. І. Перехрест, Р. В. Іванов// Вісник ДНУ. - 2002. Механіка. Вип. 6, т. 1. - С. $60-64$.

2. Перехрест В. І. Планетарний вихор та гіпотези Лапласа і Вайцзекера// Вісник ДНУ. - 2009.- Механіка. Вип. 13, т. 2, № 5. - С. 113 - 124. 
3. Перехрест B. I. Про структури планетарних вихорів і закономірності їх обертання/ В. І. Перехрест, М. М. Осипчук// Вісник ДНУ, - 2010. - Механіка. Вип. 14, т. 1, № 5. - С. 110 - 118 .

4. Перехрест B. I. Про закон ізохронності обертання у планетарних вихорах і планетарних системах/ В. І. Перехрест, М. М. Осипчук// Вісник ДНУ. - 2011. Механіка. Вип. 15, т. 1. - С. $33-43$.

5. Перехрест B. I. Закон планетних відстаней у вихровій теорії планетарних систем// Вісник ДНУ. - 2011. - Механіка. Вип 15, т. 1. - С. 21 - 33.

6. Перехрест B. I. Про об'єми, маси та кінетичні моменти структур планетарного вихору/ В. І. Перехрест, М. М. Осипчук// Вісник ДНУ. - 2012. - Механіка. Вип. 16 , т. 1 , № 5 . - С. $70-79$.

7. Алъфвен $X$. Структура и эволюционная история Солнечной системы / Х. Альфвен, Г. Аррениус// - К., 1981. - 332 с.

8. Сафронов B. C. Эволюция допланетного облака и образование Земли и планет. - M. : Наука, 1969. - 244 c.

9. Peter Bodenheimer Multiple fragmentataion of protostars/ Peter Bodenheimer (Lick Obs.), Andreas Burkert (Max-Planck In-t fur Astroph.), Richard J. Klein (Univ. of Calif.), Alan Boss (Carnegie In-t of Washington)// Protostars\&Planets IV Arizona Press. 2000. P. $675-701$.

10. Boss A. P. Gas giant protoplanet formation: Disk instability models with thermodynamics and radiative transfer// Astroph. J. - 2004. - 599. - P. $577-581$.

11. Mudryk I. R. RAPID: A fast, high resolution, flux-conservative algorithm desined for planet-disk interaction/ I. R. Mudryk, N. W. Murray// arXiv:0812.2938v1 [astro-ph] 15 Dec 2008. Toronto, Publ. CITA.

12. Кононович Э. В. Общий курс астрономии./ Э. В. Кононович, В. И. Мороз//М., МГУ. : Эдиториал УРСС. - $2004-344$ с.

13. NASA "Sun Fact Sheet"- http://nssds.gfsc.nasa.gov/planetary 2009

14. http://exoplanets.org/exotable/exotable.html 